\title{
Assessment of a Low Temperature Closed-Cycle Grain Drying System
}

\author{
Mingjun $\mathrm{Ma}^{1} \&$ Kurt A. Rosentrater ${ }^{2}$ \\ ${ }^{1}$ Department of Agricultural and Biosystems Engineering, Iowa State University, Ames, Iowa, USA \\ Correspondence: Kurt A. Rosentrater, Department of Agricultural and Biosystems Engineering, Iowa State \\ University, Ames, Iowa, USA. Tel: 1-515-294-4019. E-mail: karosent@iastate.edu
}

Received: February 10, 2019

Accepted: February 22, 2019 Online Published: March 4, 2019

doi:10.5539/jfr.v8n2p80

URL: https://doi.org/10.5539/jfr.v8n2p80

\begin{abstract}
This study analyzed the drying efficiency of a prototype low temperature closed-cycle grain drying system. The main principle of this drying system was the heat pump system working as a dehumidifier. The main component of this drying equipment included a compressor, a condenser, twin evaporators, and a fan. Two drying studies (denoted as trial 1 and trial 2) were conducted to assess the overall drying performance of this low temperature drying system. To calculate the drying efficiency, the total energy consumption was divided by the amount of water removal for each trial; the drying efficiency was reported in the form of Btu/lb of water removal. We also tested corn seed germination to determine if this drying process had an effect on seed germination performance. The drying efficiency results for trial 1 and 2 were $1036 \mathrm{Btu} / \mathrm{lb}$ water removal and $869 \mathrm{Btu} / \mathrm{lb}$ water removal, respectively; compared to other on-farm drying methods this drying system had fairly high drying efficiency. The germination test results showed that this drying system had no adverse effect on germination performance.
\end{abstract}

Keywords: grain, drying, heat pump, Low temperature, preservation

\section{Introduction}

For corn production in Iowa, on-farm drying was the major way for post harvest corn drying. Most of the on-farm grain dryers were high temperature dryer. Although high temperature grain drying was much faster, it will result in reduce of the grain quality and germination performance. Seyedin et al. (1984) reported that the corn seed germination performance could be significantly reduced by high temperature drying and by analyzing the shoot and root dry matter the seedling vigor was also significantly reduced. The maximum grain drying temperature was reported by Hall (1980), for corn used as seed the maximum safe temperature was $43{ }^{\circ} \mathrm{C}$ while for commercial corn the maximum safe drying temperature was $54{ }^{\circ} \mathrm{C}$. The highest $82{ }^{\circ} \mathrm{C}$ safe drying temperature was the corn used as animal feed. This indicates that low temperature grain drying was important for seed or commercial used corn.

From energy usage perspective, grain drying is an energy intensive process (Gunasekaran \& Thompson, 1986). For most of the grain production, the energy required for grain drying often higher than the energy usage for producing grain from seed to harvest (Verma \& Jacobsen, 1987; Enlow, 1982). The heat pump grain drying concept was early investigated by Davis (1949), Shove (1953), Shove (1973), and Flikke et al. (1957), and they found the system was not attractive economically for the then-prevailing fuel prices. More recently, since the fossil fuel prices have increased substantially, Prasertsan \& Saen-Saby (1998) found that the heat pump drying was more competitive than electrically heated dryers and direct-fired dryer due to the lowest operating cost.

This study was conducted to analyze the efficiency of the prototype low temperature closed-cycle grain drying system and its effects on seed germination. Two trials have been done in this study. The energy consumption and amount of moisture removal were measured for each trial.

\section{Materials and Methods}

The drying apparatus assessed in this study was a low temperature closed-cycle grain drying system provided by the Loebach Brothers (David R. Loebach and Joseph E. Loebach, Loebach Brothers Inc., Idaho, USA). Figure 1 shows overall layout of this drying system, the drying apparatus connected with the drying chamber by two air pipes, the dried air goes into the bottom of the chamber while the moist air goes into the drying apparatus via the top of the chamber. 


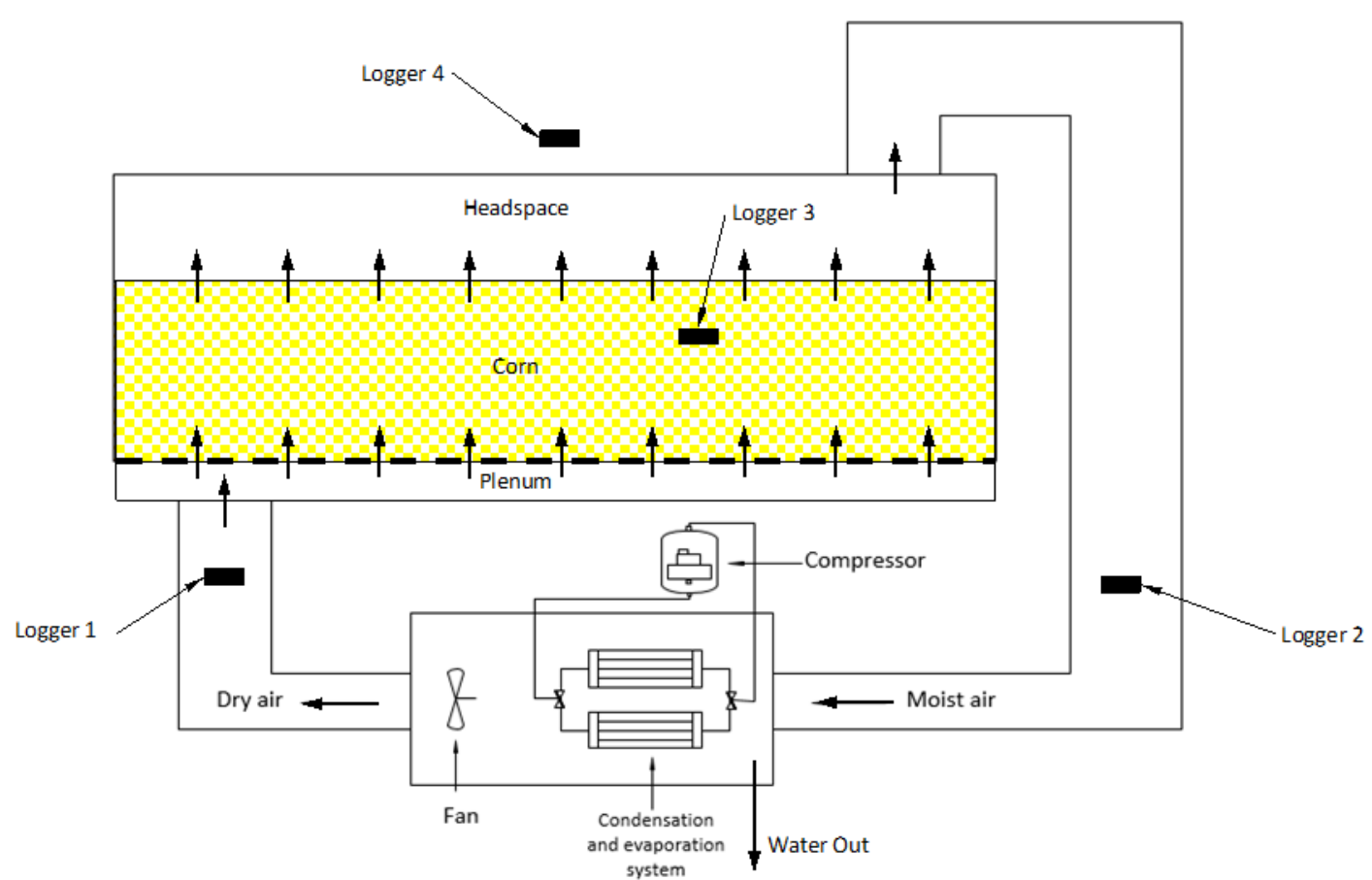

Figure 1. Overall schematic of the low temperature closed-cycle drying system and logger positions

Figure 2 shows the simple diagram of this low temperature drying system. The core part of this drying apparatus including a compressor (Copeland CF06K6E-PFV-979, Emerson Climate Technologies Incorporated, Sidney, $\mathrm{OH}, \mathrm{USA})$, a condensation-evaporation system including a condenser and twin evaporators, and a centrifugal blower (GE motors 5KCP39KGV804S, 0.5 hp, GE Energy Management, Atlanta, GA, USA). Electricity was the only energy source for this system. By controlling the four solenoid valves this drying system could run with one evaporator cooling and other evaporator heating, at present, the timer will reverse the solenoid value to allow the first evaporator to defrost and heat and the second evaporator to cool and remove mositure.

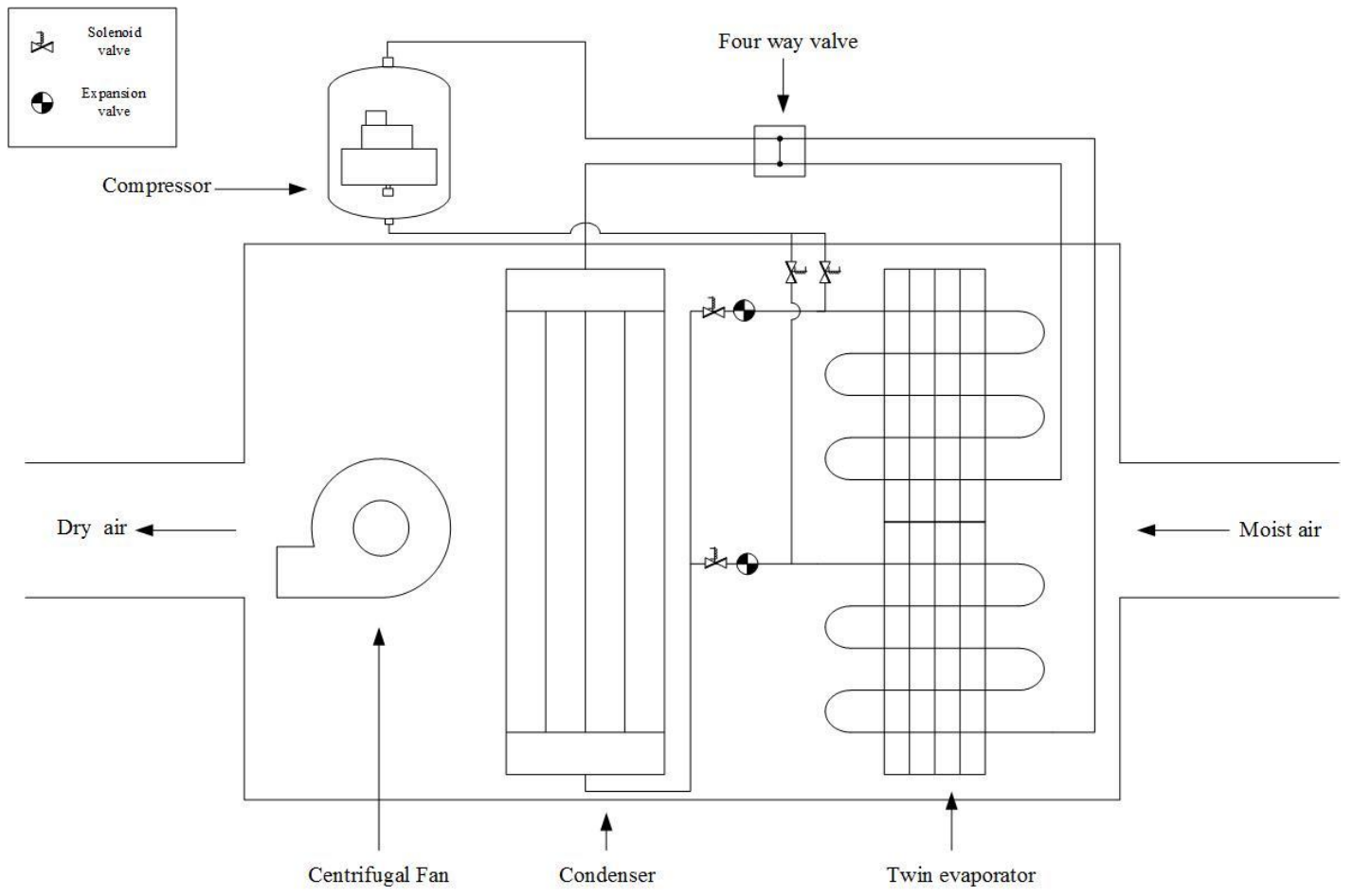

Figure 2. Detailed schematic of the compressor/drying system 
The corn was harvested by Richard Vanderpool's group and stored at the Bio-Century Research Farm (Iowa State University, Boone, IA). The initial corn wet basis moisture content was $28.1 \%$ to $28.3 \%$.

The energy consumption was measured by a power meter (Landis+Gyr MX-92-270-908, Landis+Gyr AG, Alpharetta, GA, USA) that was attached to the drying system. Four temperature loggers (Omega OM-EL-USB-2-LCD, Omega Engineering, Inc., Stamford, CT, USA) were used to record the air relative humidity and air temperature, separately for high moisture air leaving the corn, dry air leaving the drying/compressing equipment, air from 12 in below the corn surface, and ambient air for both of the drying trials (Figure 1). The moisture content of corn was measured by using a handheld moisture analyzer (Mini GAC Plus, DICKEY-John Corp.), and the corn moisture content recorded every 24 hours to track the moisture content change over time. Three replications were done to measure the corn moisture content, and the averages and standard deviations were calculated and reported in the results section.

For trial 1, the corn with the weight of $2880 \mathrm{lbs}$ and moisture content of $28.1 \%$ wet basis was placed into the chamber before the drying process. Based on the corn moisture content results during the drying process and the suggestion of the Loebach brother's the drying process was operated for 68 hours after drying process started.

For trial 2, the corn with the weight of $3200 \mathrm{lbs}$ and moisture content of $28.3 \%$ wet basis was placed into the chamber before the drying process. Based on the corn moisture content results during the drying process and the suggestion of the Loebach brother's the drying system was operated for 66.5 hours after drying process started. Corn was sampled before and after the drying process for a germination test.

For airflow rate about this low temperature grain drying system, the airflow static pressure was measured during the trial 2. The total air flow rate during trial 2 was calculated based on Shedd's curves, which quantifies resistance to airflow of grains and seeds. Figure 3 shows the dimension of the chamber that held the corn, which use to compute the aeration area and the corn depth.

119 in

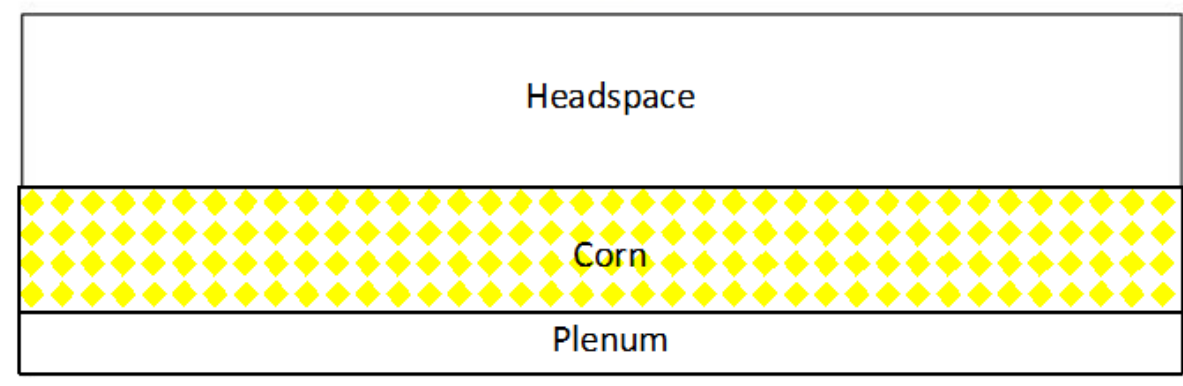

Front view

57 in

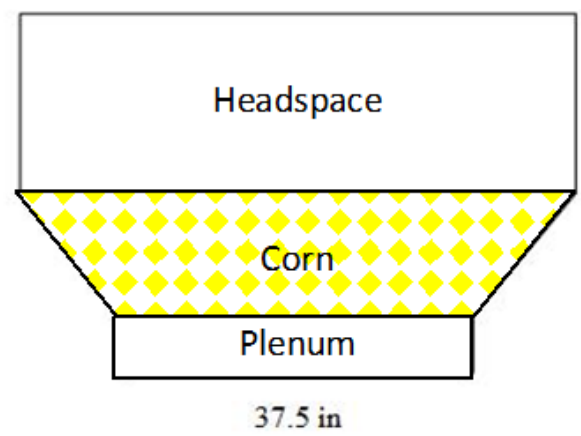

39 in

Side view

Figure 3. Overall dimensions of the drying system (drying chamber)

The corn germination performance was tested by using an incubator (Fisher Scientific Isotemp Incubator 650D, Thermo Fisher Scientific, Waltham, MA 02451). The germination test followed the procedure provided by Williams et al. (2014) which randomly picked up 50 kernels of corn and put them between two pieces of wet 
paper towels. Then rolled the two wet paper tower together with corn kernels and sealed them in a plastic bag. Put the plastic bag in an incubator for seven days at $30{ }^{\circ} \mathrm{C}$. After accounted the number of germinated corn kernels, the germination rate was computed by dividing the germinated corn kernels number by the initial 50 corn kernels. The germination test was done three times both mean and the standard deviation were calculated and reported in the results section.

The drying efficiency was determined by calculating the ratio between power consumption (Btu) and water removal (lb) and the result Btu/lb of water removal was reported:

$$
\text { Drying efficiency }=\frac{\text { energy consumption }(\mathrm{kWh})}{\text { water removal }(\mathrm{b})}
$$

The water removal (lb) was calculated by subtracting the amount of water (lb) in the corn after drying process from the total amount of water (lb) in the corn before drying process.

\section{Results and Discussion}

\subsection{Drying Data Collection and Calculation}

The drying data for the two drying trials were reported in Table 1; the mean and standard deviation for each drying parameter were also calculated and reported.

Table 1. Overall drying data collected during the study

\begin{tabular}{lll|ll}
\hline Grain drying data & Trial 1 & Trial 2 & Mean & St Dev. \\
\hline Drying time (h) & 68 & 66.5 & 67.25 & 0.75 \\
Initial corn moisture content (\%) & 28.1 & 28.3 & 28.2 & 0.1 \\
Initial corn weight (lb) & 3460 & 4000 & 3730 & 270 \\
Moisture content after drying (\%) & 14.3 & 12.9 & 13.6 & 0.7 \\
Corn weight after drying(lb) & 2880 & 3200 & 3040 & 160 \\
Water removal (lb) & 560 & 707 & 633.5 & 73.5 \\
Power consumption (kWh) & 170 & 180 & 175 & 5 \\
Drying efficiency (Btu/lb water removed) & 1036 & 869 & 952.5 & 83.5 \\
Drying efficiency (kWh/lb water removed) & 0.30 & 0.25 & 0.275 & 0.025 \\
\hline
\end{tabular}

The initial corn moisture content was measured as $28.1 \%$ and $28.3 \%$ for trial 1 and trial 2, respectively with the average value $28.2 \%$ and the standard deviation 0.1 . For trial 1 the overall drying time was recorded as 68 hours and 66.5 hours, respectively, for trial 1 and trial 2. The average dry time for this drying system was calculated as 67.25 hours. The initial corn weight for trial 1 was measured as $3460 \mathrm{lb}$ while for trial 2 the initial corn weight was $4000 \mathrm{lb}$. The mean of initial corn weight was calculated as $3730 \mathrm{lb}$ with the standard deviation value 270 . The drying power consumption were measured as $170 \mathrm{kWh}(580064 \mathrm{Btu})$ and $180 \mathrm{kWh}(614185 \mathrm{Btu})$ for trial 1 and trial 2, respectively. The average power consumption for this drying system was calculated as $175 \mathrm{kWh}$ $(597125 \mathrm{Btu})$ with the standard deviation of $5 \mathrm{kWh}(17060.7 \mathrm{Btu})$. The final corn moisture content was measured as $14.3 \%$ and $12.9 \%$ for trial 1 and trial 2, respectively. The average dried corn moisture content was $13.6 \%$ and the standard deviation was $0.7 \%$. The total water removal during drying process was $560 \mathrm{lb}$ in trial 1 and $707 \mathrm{lb}$ in trial 2. The drying efficiency was calculated as $0.30 \mathrm{kWh} / \mathrm{lb}$ of water removal (1036 Btu/lb of water removal) and $0.25 \mathrm{kWh} / \mathrm{lb}$ of water removal $(869 \mathrm{Btu} / \mathrm{lb}$ of water removal) for trial 1 and trial 2, respectively. The system average drying efficiency was calculated as $0.275 \mathrm{kWh} / \mathrm{lb}$ of water removal (953 Btu/lb of water removal) of water removal, with the standard deviation of $0.025 \mathrm{kWh} / \mathrm{lb}$ of water removal $(68.9 \mathrm{Btu} / \mathrm{lb}$ of water removal). Comparing drying equipment efficiency from trial 1 and trial 2, the equipment in trial 2 was $16 \%$ more efficient than the equipment in trial 1 . The trial 1 and trial 2 was conducted under a similar temperature condition which was 13 to 25 degree Celsius, the main reason caused the efficiency difference was before we started the trial 1 the whole drying system had not been operated for a while, and it took time to get the drying system work in the best condition and start to remove water from the corn. Zhang (2015) conducted a similar corn drying project which used the same drying system with the present study. In Zhang's study, two trials including fall trial and winter trial were conducted to measure the drying efficiency. The drying efficiency in Zhang's work was reported as $1480 \mathrm{Btu} / \mathrm{lb}$ of water removal and $2760 \mathrm{Btu} / \mathrm{lb}$ of water removal for fall and winter trials, respectively. Compared to Zhang's results the drying system in the present study was $36 \%$ and $65 \%$ more efficient. The reason for the drying efficiency difference could be because of the difference of the initial corn moisture content and dried moisture content. The original corn moisture content in Zhang's study was $18.9 \%$ which was about 33\% lower than that in the present study. The drying system will always run at low efficiency when the initial grain 
moisture content is relatively low. The air temperature also had a significant effect on drying efficiency. In Zhang's winter trial, the corn was dried from $18.9 \%$ moisture content to $14.1 \%$ moisture content, and the working air temperature was between $-3{ }^{\circ} \mathrm{C}$ to $10{ }^{\circ} \mathrm{C}$, while in the present study the average working air temperature was $24.3^{\circ} \mathrm{C}$. Hanna et al. (2014) reported the energy consumption during grain drying using several different drying methods, including batch in bin systems and counter-flow style dryers; their result showed that drying efficiency ranged from 2000-3000 Btu/lb of water removed, which thus consumed 52\%-68\% more energy to remove one pound of water compared to the present study. Morey et al. (1978) observed $5.7 \mathrm{MJ} / \mathrm{kg}$ (2461 $\mathrm{Btu} / \mathrm{lb}$ ), and the present system was also more efficient. Compared to Wilcke \& Bern (1986), which was 3.02 $\mathrm{MJ} / \mathrm{kg}(1300 \mathrm{Btu} / \mathrm{lb})$, the present system was more efficient and had a shorter drying period.

For air flow rate, the static air pressure during trial 2 was measured as 0.41 in of water, based on the calculation the average aeration area was $39 \mathrm{ft}^{2}$ the corn depth was $1.65 \mathrm{ft}$. The pressure drop per unit depth was computed as 0.25 in of water per 1 foot of corn which means from the Shedd's curve the air flow for shield corn was 25 $\mathrm{cfm}$ per 1 square foot. The total airflow rate was computed as $975 \mathrm{cfm}$.

\subsection{Air Temperature and Relative Humidity Results}

Figures 4 and 5 shows the air temperature and relative humidity value recorded by the four loggers. For trial 1 , it was clear to see that all the air temperature and dew point temperature for logger 1 , logger 2 and logger 3 all had the similar trend with logger 4. Also, at the same period, all the temperature value remained at the same level, except for the air temperature before drying the corn was higher than air temperature after drying the corn. For trial 2 the temperature result was resembled with trial 1 , since the drying system operated under similar temperature.
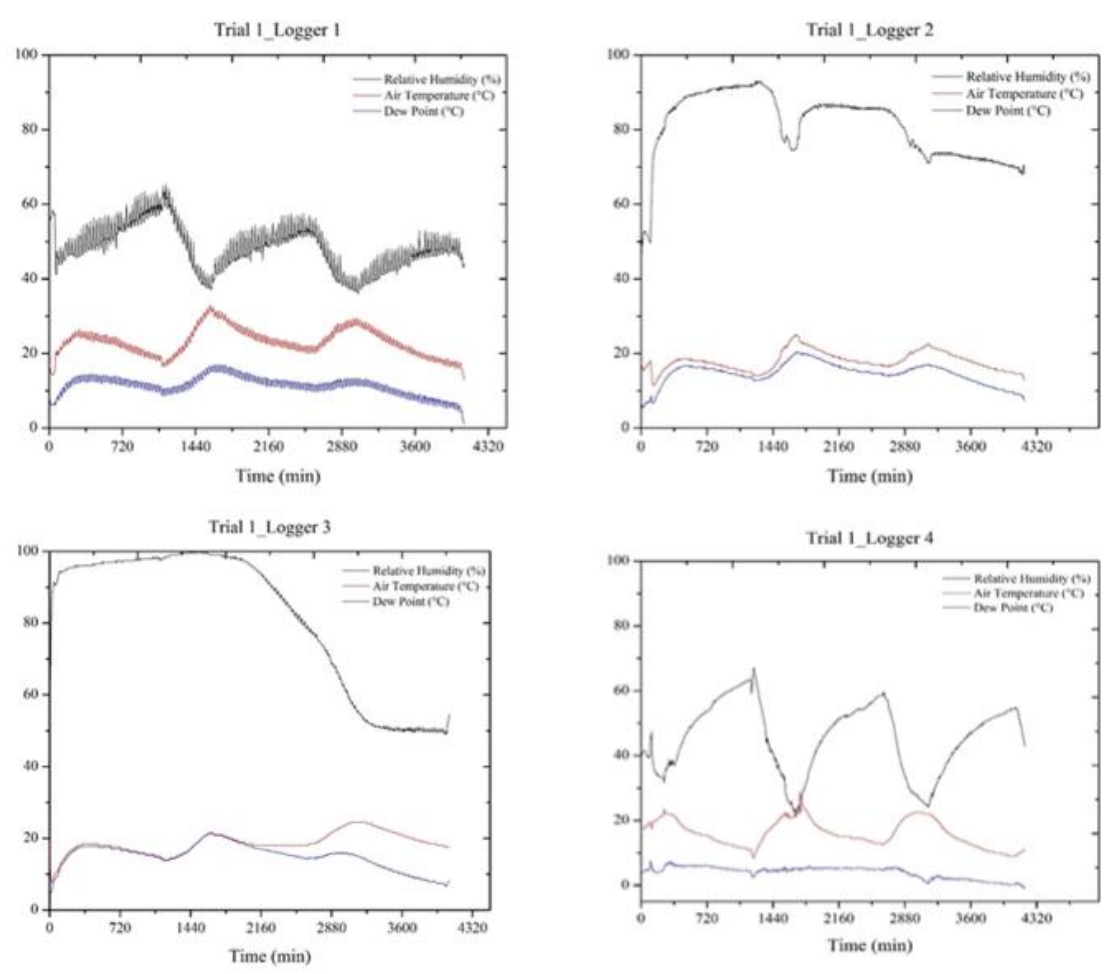

Figure 4. Air temperature and relative humidity for trial 1 

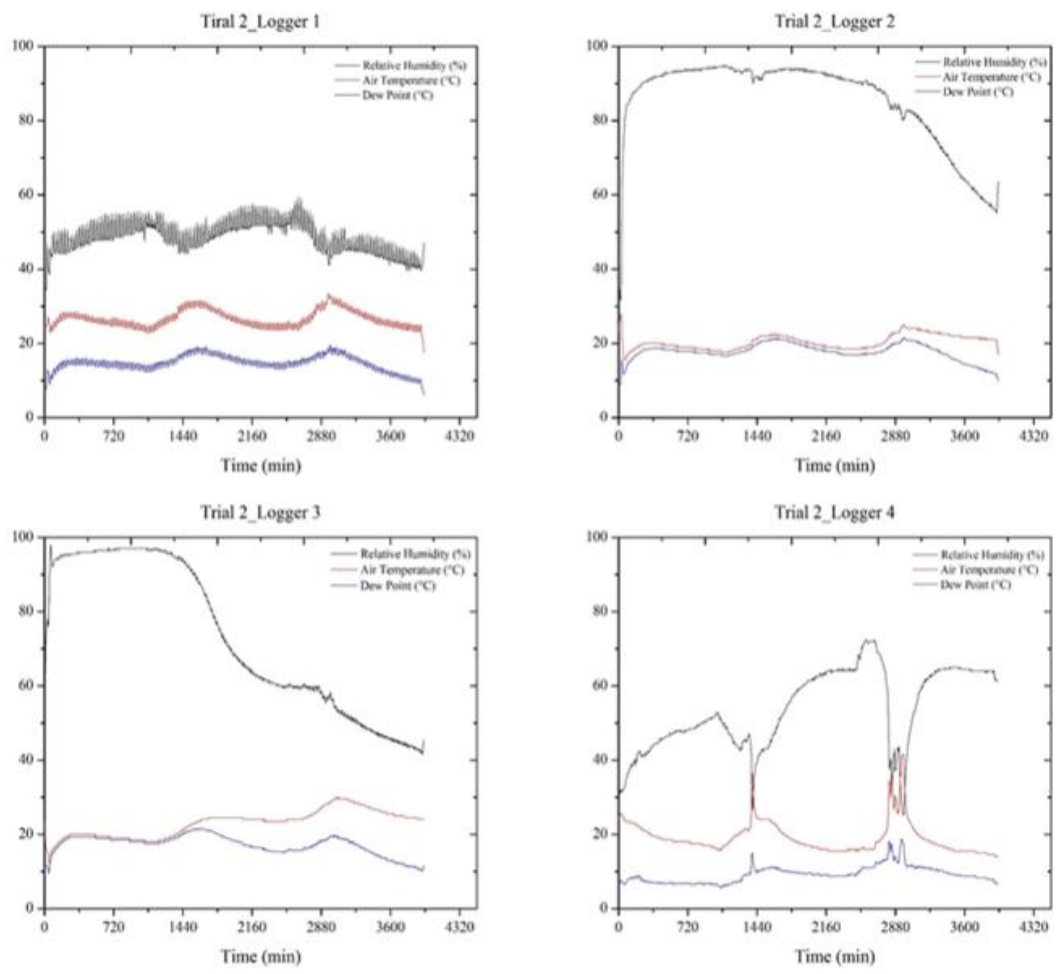

Figure 5. Air temperature and relative humidity for trial 2

For air temperature result the means and the standard deviation were calculated and reported in Table 2 and Table 3. For trial 1 the average air temperature was $22.9^{\circ} \mathrm{C}, 17.7^{\circ} \mathrm{C}, 18.6{ }^{\circ} \mathrm{C}$, and $15.9^{\circ} \mathrm{C}$ for logger 1 , logger 2 , logger 3 , and logger 4 , respectively. For trial 2 the average air temperature was $25.5^{\circ} \mathrm{C}, 20.1^{\circ} \mathrm{C}, 22.5^{\circ} \mathrm{C}$, and $18.9^{\circ} \mathrm{C}$ for logger 1 , logger 2 , logger 3 , and logger 4 , respectively. The statistical analyses showed that all the temperature results were significantly different from each other, even though some loggers read very high standard deviations (see Figures 4 and 5). Much of the deviations for loggers 2, 3, and 4 can be explained by diurnal changes in temperature and relative humidity over the course of the study (i.e., daily temperatures and humidities were not constant), which is shown by fairly slow changes in each data stream over time. For logger 1 (where diurnal changes were also evident), short but frequent variations in temperatures and humidities were recorded for this logger and were due to the frequent switching of the evaporators between the heating and cooling operations.

For different loggers, the average air temperature was $24.3^{\circ} \mathrm{C}, 18.9^{\circ} \mathrm{C}, 20.6^{\circ} \mathrm{C}$, and $17.5^{\circ} \mathrm{C}$ for logger 1 , logger 2 , logger 3 , and logger 4, respectively. From Figures 6 and 7 it was clear that the dry air temperature was higher than other air temperature. The air temperature will decrease when carrying water out from the corn.

For dew point temperature results the means and the standard deviation were calculated and reported in Table 2 and Table 3. For trial 1 the average air temperature was $11.3^{\circ} \mathrm{C}, 14.2^{\circ} \mathrm{C}, 14.5^{\circ} \mathrm{C}$, and $3.7^{\circ} \mathrm{C}$ for logger 1 , logger 2, logger 3 and logger 4, respectively. For trial 2 the mean dew point temperature was $13.8^{\circ} \mathrm{C}, 16.6^{\circ} \mathrm{C}, 16.2^{\circ} \mathrm{C}$, and $9.0^{\circ} \mathrm{C}$ for logger $1, \operatorname{logger} 2, \operatorname{logger} 3$, and $\operatorname{logger} 4$, respectively. The statistical analysis showed that all the temperature results were significantly different from each other. For various logger, the average air temperature was $12.6{ }^{\circ} \mathrm{C}, 15.4{ }^{\circ} \mathrm{C}, 15.3^{\circ} \mathrm{C}$, and $6.42^{\circ} \mathrm{C}$ for logger 1 , logger 2 , logger 3 , and logger 4 , respectively. From Figures 6 and 7, it was evident that the dry air dew point temperature was lower than the moist air and the air inside the corn mass, which means the drying system work ideal for move the moisture out of the system. 


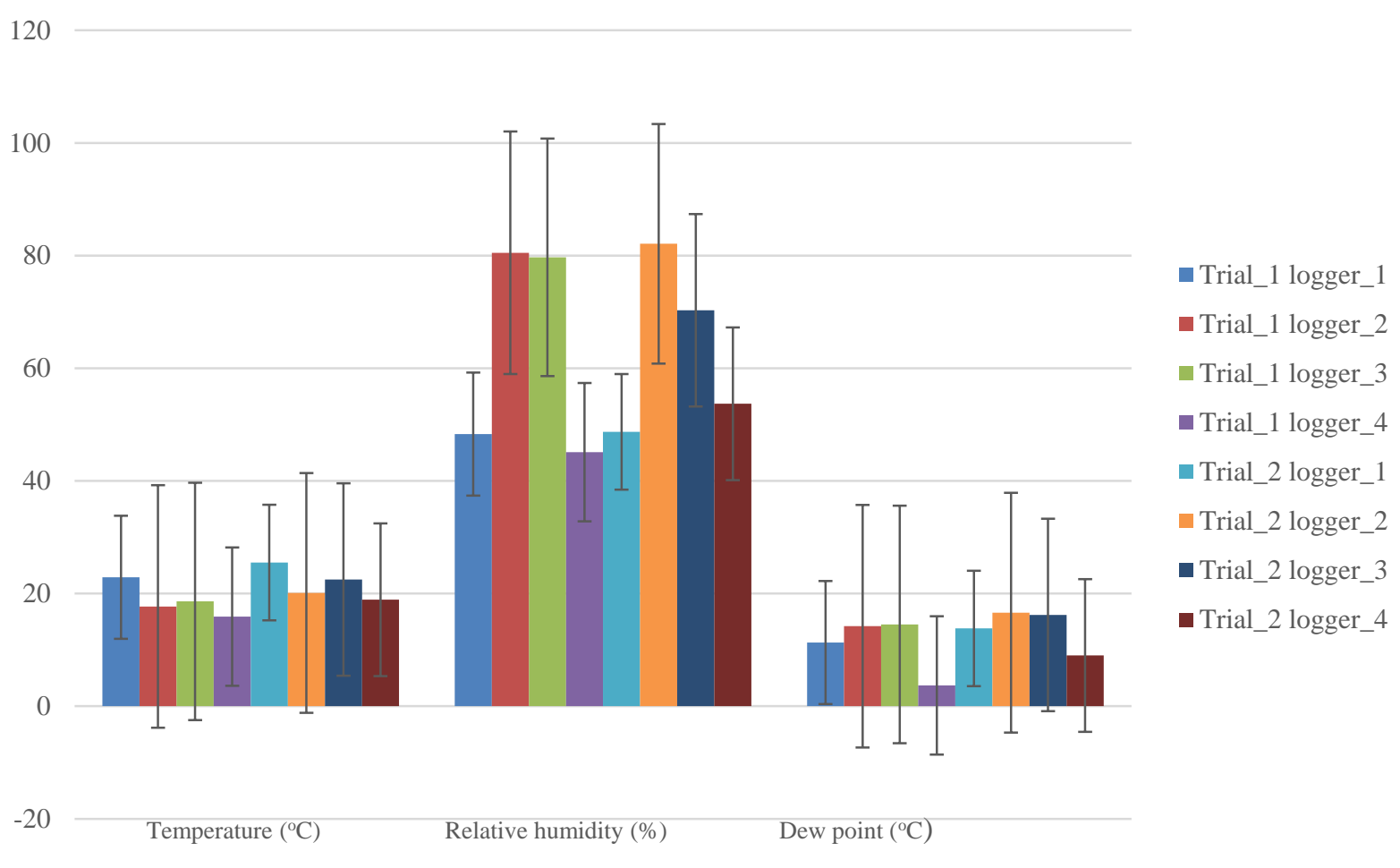

Figure 6. Mean air temperatures and relative humidities for trial 1 and trial 2

(Error bars indicate standard deviation)

Table 2. Mean air temperature and relative humidity data for various trials and loggers*

\begin{tabular}{lllll}
\hline Air properties & Logger1 & Logger2 & Logger3 & Logger4 \\
\hline Trial 1 & & & & \\
\hline Temperature $\left({ }^{\circ} \mathrm{C}\right)$ & $22.9(3.7) \mathrm{a}$ & $17.7(2.7) \mathrm{b}$ & $18.6(2.8) \mathrm{c}$ & $15.9(4.1) \mathrm{d}$ \\
Relative humidity $(\%)$ & $48.3(6.1) \mathrm{a}$ & $80.5(9.5) \mathrm{b}$ & $79.7(20.5) \mathrm{b}$ & $45.1(10.9) \mathrm{c}$ \\
Dew point $\left({ }^{\circ} \mathrm{C}\right)$ & $11.3(2.6) \mathrm{a}$ & $14.2(3.3) \mathrm{b}$ & $14.5(3.9) \mathrm{b}$ & $3.7(2.1) \mathrm{c}$ \\
\hline Trial 2 & & & & \\
\hline Temperature $\left({ }^{\circ} \mathrm{C}\right)$ & $25.5(3.8) \mathrm{a}$ & $20.1(2.3) \mathrm{b}$ & $22.5(3.7) \mathrm{c}$ & $18.9(4.2) \mathrm{d}$ \\
Relative humidity $(\%)$ & $48.7(4.4) \mathrm{a}$ & $82.1(14.6) \mathrm{b}$ & $70.3(20.4) \mathrm{c}$ & $53.7(10.3) \mathrm{d}$ \\
Dew point $\left({ }^{\circ} \mathrm{C}\right)$ & $13.8(3.2) \mathrm{a}$ & $16.6(3.6) \mathrm{b}$ & $16.2(3.7) \mathrm{c}$ & $9.0(2.2) \mathrm{d}$ \\
\hline
\end{tabular}

* Different letters after means for each value of the air properties indicates significant difference at $\alpha=0.05$; the standard deviation is reported in parentheses 


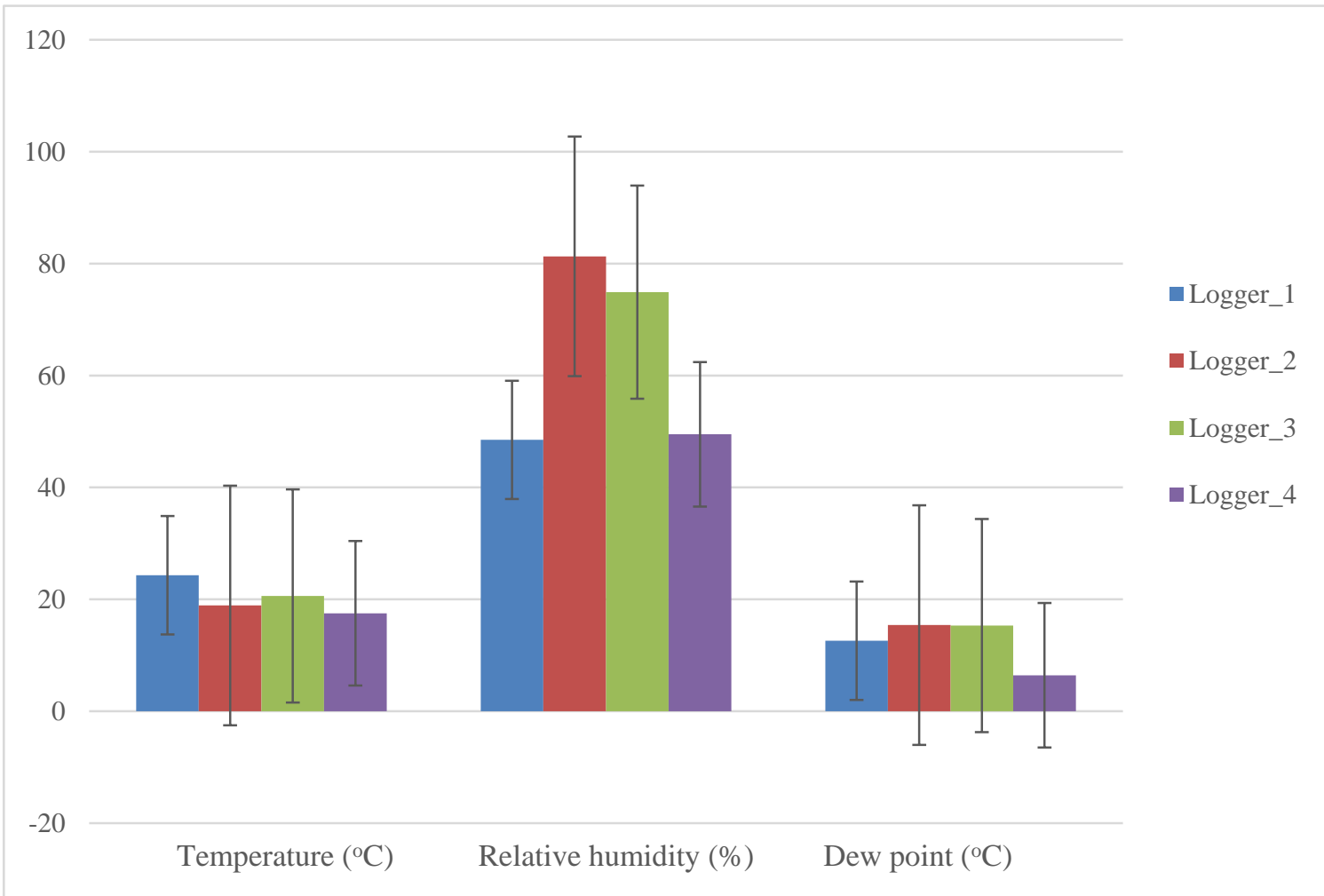

Figure 7. Mean air temperatures and relative humidities for the various loggers

(Error bars indicate standard deviation)

Table 3. Overall mean air temperature and relative humidity data for each logger*

\begin{tabular}{lllll}
\hline Air properties & Logger1 & Logger2 & Logger3 & Logger4 \\
\hline Temperature $\left({ }^{\circ} \mathrm{C}\right)$ & $24.3(3.9)$ & $18.9(2.7)$ & $20.6(3.8)$ & $17.5(4.4)$ \\
Relative humidity $(\%)$ & $48.5(5.2)$ & $81.3(12.4)$ & $74.9(20.9)$ & $49.5(11.5)$ \\
Dew point $\left({ }^{\circ} \mathrm{C}\right)$ & $12.6(3.2)$ & $15.4(3.7)$ & $15.3(3.9)$ & $6.42(3.4)$ \\
\hline
\end{tabular}

* The standard deviation is reported in parentheses

For relative humidity result, compare the relative humidity value before and after drying the corn. A significant 20 to 30 percentage point relative humidity drop can be observed (Figure 7), which illustrates the drying system could effectively change the relative humidity. Figure 7 shows the relative humidity change happened inside the corn.

For relative humidity result, approximate 40 percentage point relative humidity drop can be observed between the relative humidity value before and after drying the corn (Figures 6 and 7). This illustrates that the drying apparent can effectively change the relative humidity and compare this value with trial 1 , which was 20 to 30 percentage point relative humidity drop, the drying system was more efficient on trial 2 . For the air relative humidity inside the corn, a significant decrease can be observed after the drying process started 1440 minutes while in trial 1 the air relative humidity inside the corn dropped at 1800 minutes after the drying process started. This time, the difference also shows that the drying system was more efficient during trial 2.

\subsection{Corn Seed Germination Test}

Table 4 shows the germination test results. For the initial corn, the average germinated corn was 44.3 , and the germination rate was 0.88 , while for the dried corn the average germinated corn was 45 and the germination rate was 0.9 . The statistical analysis showed that for germinated corn and germination rate there was no significant difference between initial corn and dried corn at $\alpha=0.05$. The results indicated this low temperature grain drying system had no negative effect on corn seed germination performance. 
Table 4. Germination test results*

\begin{tabular}{lllll}
\hline Germination test & Replication & Number Corn Seeds & Germinated Corn & Germination Rate \\
\hline \multirow{4}{*}{ Initial Corn } & 1 & 50 & 43 & 0.86 \\
& 2 & 50 & 44 & 0.88 \\
& 3 & 50 & 46 & 0.92 \\
\cline { 2 - 5 } & Mean & 50 & $44.3 \mathrm{a}$ & $0.88 \mathrm{a}$ \\
& St Dev. & 0 & 1.5 & 0.03 \\
\hline \multirow{5}{*}{ Dried Corn } & 1 & 50 & 45 & 0.9 \\
& 2 & 50 & 44 & 0.88 \\
& 3 & 50 & 46 & 0.92 \\
\cline { 2 - 5 } & Mean & 50 & $45 \mathrm{a}$ & $0.9 \mathrm{a}$ \\
& St Dev. & 0 & 1 & 0.02 \\
\hline
\end{tabular}

*Differing letters after means for either germinated corn or germination rate indicate a significant difference at $\alpha=0.05$ between initial and dried corn

\section{Conclusions}

The present study shows that the closed cycle low temperature drying system was more efficient than most of the drying system that used for the on-farm operation. The heat pump system could remove water effectively by reducing the air dew point temperature. Air temperature and corn initial moisture content could have an effect on overall drying efficiency. Compare to other low temperature drying system; the present system will significantly save the overall drying time. The present drying system had no negative effect on seed germination performance.

\section{Acknowledgements}

The authors would like to thank: C. J. Bern for assistance with understanding the heat pump system and for reviewing earlier versions of this manuscript and providing constructive comments and feedback, as well as David and Joseph Loebach for use of their innovative drying system.

\section{References}

Davis, C. P. (1949). A study of the adaptability of the heat pump to drying shelled corn. Unpublished M.S. thesis, Purdue Univ., West Lafayette, IN, USA.

Enlow, R. W. (1982). Energy research for the farm. Agricultural Information Bull., 447, No. 447, U.S. Department of Agriculture, Washington, D.C.

Flikke, A. M., Cloud, H. A., \& Hustrulid, A. (1957). Grain drying by heat pump. Agricultural Engineering, 38(8), 592-597.

Gunasekaran, S., \& Thomson, T. L. (1986). Optimal energy management in grain drying. Critical Reviews in Food Science and Nutrition, 25(1), 1-48. https://doi.org/10.1080/10408398609527444

Hall, C. W. (1980). Drying and storage of agricultural crops. Westport, CT: AVI.

Morey, R. V., Gustafson, R. J. Cloud, H. A., \& Walter, K. L. (1978). Energy requirements for high-low temperature drying. Transactions of the ASAE, 21(3), 562-567. https://doi.org/10.13031/2013.35345

Prasertsan, S., \& Saen-Saby, P. (1998). Heat pump drying of agricultural materials. Drying Technology, 16(1-2), 235-250. https://doi.org/10.1080/07373939808917401

Seyedin, N., Burris, J. S., \& Flynn, T. E. (1984). Physiological studies on the effects of drying temperatures on corn seed quality. Can. J. Plant Sci., 64, 497-504. https://doi.org/10.4141/cjps84-072

Shove, G. C. (1953). A laboratory investigation of the adaptability of the heat pump to batch drying of shelled corn. Unpublished MS thesis, Kansas State University, Manhattan, KS, USA.

Shove, G. C. (1973). Temperature cycling enhances deep bed drying. Am. Soc. Agric. Engrs Paper 73-323, St. Joseph, MI, USA.

Verma, L. R., \& Jacobsen, L. (1987). Energy used in on-farm rice drying. American Society of Agricultural Engineers, paper No. 82-3010, St. Joseph, MI, USA.

Wilcke, W. F., \& Bern, C. J. (1986). Natural-air corn drying with stirring: II. Dryer performance. Transactions of the ASAE, 29, 860-867. https://doi.org/10.13031/2013.30241 
Williams, S. B., Baributsa, D., \& Woloshuk, C. (2014). Assessing Purdue improved crop storage (PICS) bags to mitigate fungal growth and aflatoxin contamination. Journal of Stored Products Research, 59, 190-196. https://doi.org/10.1016/j.jspr.2014.08.003

Zhang, C. (2015). Analysis and modeling of agricultural processing with regard to grain post-harvest handling and winemaking. Unpublished MS thesis, Iowa State University, Ames, IA, USA.

\section{Copyrights}

Copyright for this article is retained by the author(s), with first publication rights granted to the journal.

This is an open-access article distributed under the terms and conditions of the Creative Commons Attribution license (http://creativecommons.org/licenses/by/4.0/). 